\title{
Norwegian adolescents, physical activity and mental health: The Young-HUNT study
}

\author{
Ida Slettbakk Fløtnes, Tom Ivar Lund Nilsen and Liv Berit Augestad \\ Department of Human Movement Science, Faculty of Social Science and Technology Management, \\ Norwegian University of Science and Technology (NTNU), 7491 Trondheim, Norway \\ Correspondence: Liv Berit Augestad $\quad$ E-mail: Liv.Berit.Augestad @svt.ntnu.no Telephone: +4773591771 Telefax +4773591770
}

\begin{abstract}
Background: The aim of the study was to examine the associations of physical activity, sport participation, and body composition on the risk of symptoms of mental health problems in a large population-based sample of Norwegian adolescents.

Methods: Analyses were based on 4-year longitudinal data from the Young-HUNT studies in Norway among 2000 adolescents aged 13-19 years. We calculated relative risks of anxiety/depression symptoms, as well as of feeling downhearted and dissatisfied with life, in relation to various measures of physical activity, sports participation, anthropometric measures, and body image.

Results: Overall, physical activity was inversely associated with the risk for anxiety/depression in boys (Ptrend, 0.02), but not in girls (P-trend, 0.34). Girls who considered themselves "very fat/chubby" had a higher risk than those who considered themselves as "about the same as others" (RR, 1.4; 95\% CI, 1.0-1.7), whereas in boys, the risk was highest for those who considered themselves as "thin/very thin" (RR, 1.7; 95\% CI, 1.1-2.7). Analysis of the risk of feeling downhearted or dissatisfied with life showed an inverse association for physical activity, both in girls and boys, and there was also a U-shaped association with body image.

Conclusion: Physical activity was inversely related to risk of anxiety/depression in boys, but not in girls, and inversely related to the risk of feeling downhearted and dissatisfied with life in both genders. Body image was strongly associated with symptoms of anxiety/depression and measures of well-being, whereas body size showed no clear associations. These results suggest that self-perception of appearance are more important for mental health in adolescents than the actual body composition, and that being physically active may be beneficial, especially among boys.
\end{abstract}

\section{INTRODUCTION}

Adolescence is a vulnerable period due to physical, cognitive, emotional and attitudinal changes, and an increased occurrence of mental health problems have been reported (Paus et al., 2008; Schonert-Reichl \& Muller, 1996; Substance Abuse and Mental Health Services Administration, 2008; Wight et al., 2004). Data from the US showed a prevalence of anxiety/depression that was considerably higher in 16- and 17-yearolds (11.8\%) than in the 12-year-olds (2.8\%) (Substance Abuse and Mental Health Services Administration, 2008), and these findings are consistent with other studies (Wight et al., 2004, Sepulveda \& Anehensel, 2004; The Institute of Public Health; 2009).

Results from population-based studies indicate that the prevalence of mental illness among adolescent girls is higher than among boys (Grøtvedt \& Gimmestad, 2002; Substance Abuse and Mental Health Services Administration, 2008). A Norwegian study of 12000 adolescents showed that gender differences emerged between 13 and 14 years of age (Wichstrøm, 1999 ), and a more recent study found that $10 \%$ of boys and $26 \%$ of girls had a symptom level that indicated existence of depression and/or anxiety (Grøtvedt \& Gimmestad, 2002). This is in agreement with data from the US, showing a prevalence of major depression episodes in adolescents aged 12-17 years that was more than twice as high among girls than among boys (Substance Abuse and Mental Health Services Administration, 2008).

Several studies have investigated the association between body composition and mental health in adolescents. Cortese et al. (2009) found that girls who were either heavier than average or underweight had the highest depression scores, whereas for boys the highest scores were found among those who were obese, and Erermis et al. (2004) showed a higher occurrence of psychopathology (e.g. depression, behavioral problems, low-esteem) among obese than among non-obese adolescents. However, other studies have not found similar associations (Daniels, 2005; Ozmen et al., 2007).

It has also been shown that physical activity has a favorable effect on mental problems in adolescence, such as depression, anxiety and conduct problems (Calfas \& Taylor, 1994; Larun et al., 2003; Motl et al., 2004, Mutrie \& Parfitt, 1998; Steptoe \& Butler, 1996). A review of 54 studies showed that the majority had found an inverse relation between physical activity and depression (Sallis et al., 2000). However, a Cochrane review on exercise in prevention and treatment of 


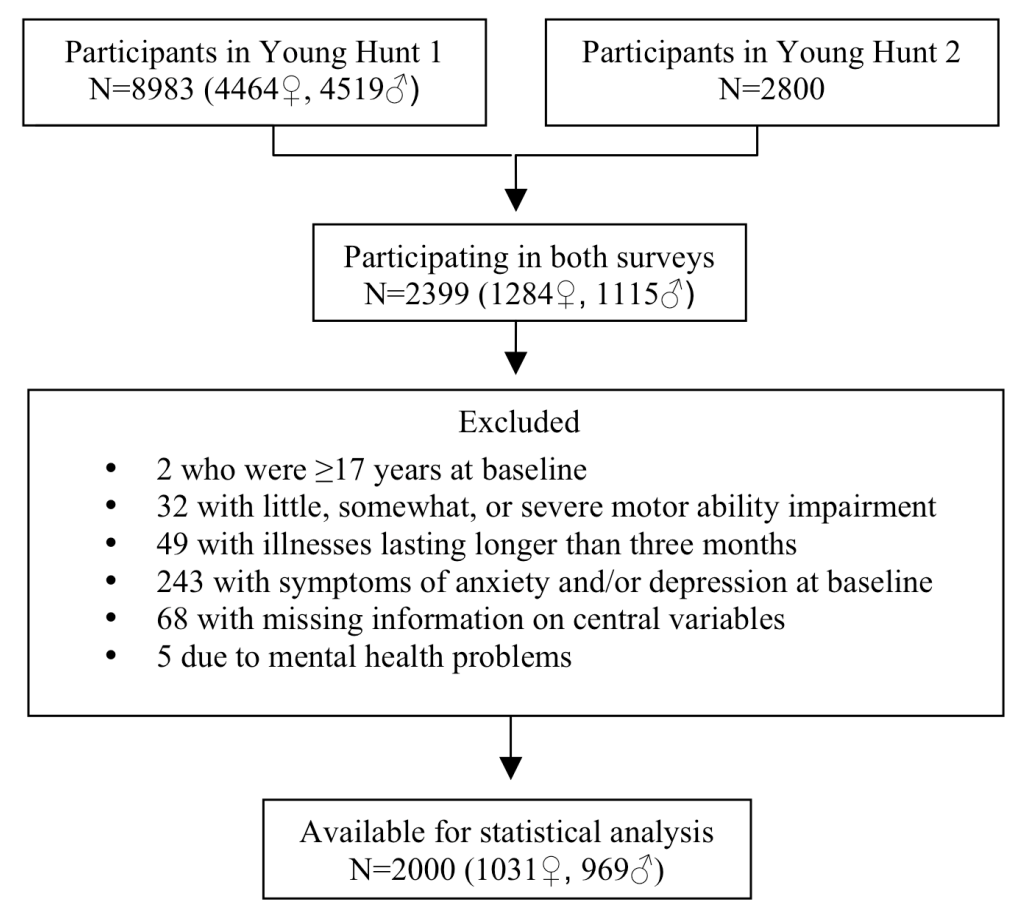

Figure 1. Flowchart showing the selection of participants for the current study.

anxiety and depression in children and adolescents concluded that exercise had only a minor effect (Larun et al., 2003). A longitudinal study from Norway found that weekly hours of physical activity at age 15-16 years may influence some aspects of mental health three years later, but these effects were only evident in boys and not in girls (Sagatun et al., 2007).

The aim of this study was to prospectively examine the associations of physical activity, sport participation, body composition, and body image on the risk for symptoms of mental health problems in a large population-based sample of Norwegian adolescents. More specifically we studied the risk for symptoms of anxiety/depression classified from a five item version of Hopkins Symptom Check List (SCL-5), and in supplementary analyses we examined these factors in relation to risks of feeling downhearted or dissatisfied with life.

\section{MATERIAL AND METHODS}

\section{Subjects}

The county of Nord-Trøndelag, in central Norway, has approximately 127000 inhabitants. Nord-Trøndelag County is demographically comparable to Norway as a whole regarding geography, economy, industry, income, age distribution, morbidity, and mortality. In 1995-1997 all inhabitants older than 13 years old was invited to join a large population study, The NordTrøndelag Health Study (HUNT 2). Students in middle schools (12-16 years old) and students in high schools (16-19 years old) were invited to attend in the adolescent part of the study, Young-HUNT 1. A total of 8983
(90\%) adolescents agreed to participate. In 2000-2001 a follow-up, Young-HUNT 2 found place. YoungHUNT 2 included the youngest participants from Young-HUNT 1, when they were in the last 2 years of high school. 2800 adolescents $(81 \%)$ took part in the study. In all, 2399 adolescents participated in both surveys. As shown in Figure 1, 399 of these were excluded, leaving 2000 adolescent for statistical analysis.

\section{Study variables}

In both surveys the adolescents completed a self administered questionnaire in school hours, and participated in a clinical examination, including measurements of height, weight, and waist/hip circumference. The main outcome variable in the completed study was mental health problems.

\section{Mental health}

Symptoms of depression and anxiety were measured with Hopkins Symptom Check List-5 (SCL-5). Previous studies have found that the SCL-5 has a good reliability (Strand et al., 2003; Tambs \& Moum, 1993). Answers were scored according to a scale ranging from "not at all bothered" (coded as 1) to "extremely bothered" (coded as 4). The mean score was calculated. To determine whether or not the adolescents were troubled with symptoms of anxiety and depression, a cut-off point was set at 2.0 (Strand et al., 2003).

Two questions measured general well-being; "Thinking about your life at the moment, would you say that you by and large are satisfied with life, or are you mostly dissatisfied?" and "Would you say you are usually cheerful or downhearted?". We used a 7-point scale 
ranging from very satisfied (coded as 1 ) to very dissatisfied (coded as 7) on the first question, and from very downhearted (coded as 1) to very cheerful (coded as 7) on the second question. From these responses we computed two new dichotomous outcome variables. Adolescents who responded 1-3 were classified as cheerful and satisfied with life, and those who responded 4-7 were classified as downhearted and dissatisfied with life.

\section{Physical activity}

The leisure time physical activity questionnaire included questions related to frequency, duration and intensity of training, and type of activity (Holmen et al., 2002; Tollefsen et al., 2006). The answers on the amount of physical activity (days and hours) were divided in 4 groups (e.g., answers from the questions of "days of physical activity" was divided in: "exercising 4 days a week or more", "exercising 2 to 3 days a week", "exercising 1 day a week, and "exercising less than 1 day a week"). Participation in different type of sports was divided in 5 groups; "endurance", "strength", "esthetics", "ball-sports", and "other sports". In addition one single item question was included in the analyses; "Are you actively involved in sports". The question had three possible answers: "Yes", "No", and "No, but I was before". Measuring physical activity using selfreport may affect the studies reliability and validity (Shepard, 2003; Ainsworth et al., 1999). Nevertheless, using self-report questionnaire in assessment of physical activity is the most practical and easiest way to collect a broad range of data from a large number of adolescents (Kohl et al., 2000; Shepard, 2003). However, two publications have found that the reliability and validity of the physical activity questions used in the present study was acceptable (Booth et al., 2001; Rangul et al., 2008).

\section{Body composition and development}

Height, waist, and hip circumference were measured to the nearest centimeter $(\mathrm{cm})$, and weight to the nearest half kilogram $(\mathrm{kg})$. To define BMI we used the International Obesity Task Force classification described by Cole et al., (2000). It includes percentile cut-off points for each sex and age (by half year) category to define underweight, normal weight, overweight, and obesity among children and adolescents. We also used waist circumference and waist-hip ratio to define the body composition of the adolescents. Validation studies have shown high correlation between waist circumference and trunk fat measured by DEXA- scan, measuring both fat and lean body-mass, among 3-19 years old children and adolescents (Daniels et al., 2000; Goran et al., 1998). The cut-offs for the waist circumference were divided into five equal groups (fifths) based on percentiles; people in the lowest and highest fifth were respectively defined as low and high, whereas the three middle fifths were categorized as medium. The same procedure was completed for the waist-hip ratio. In addition, we included a question about how the adolescents considered their body size with "very fat/chubby", "about the same as others" and "thin/very thin" as response options.

Regarding pubertal development, the adolescents rated themselves according to growth spurt and pubic hair growth. Girls were asked about age at menarche and breast development, while boys were asked to report changes in voice and facial hair growth. The adolescents were asked to report the extent of pubertal changes on a scale ranging from 1 (have not begun) to 4 (development completed). Menarche was dichotomized into yes (coded 4) and no (coded 1). The score for the four items was summarized into a total pubertal development score (PDS-score) and divided by 4 . The adolescents with PDS-scores in the lowest fifth, according to age and gender, were classified as "late", while those within the highest fifth as "early". Participants between the $20^{\text {th }}$ and $80^{\text {th }}$ percentile were classified as "on time". This procedure was adopted from Bratberg et al., (2007).

\section{Statistical analysis}

A log-binomial model, with a log link function, was used to estimate the relative risk (RR) of anxiety/ depression symptoms (SCL-5 $\geq 2$ ) associated with the various measures of physical activity and sports participation, with anthropometric measures, and with body image. In similar analyses we estimated the RR for feeling downhearted and being dissatisfied with life. Precision of the estimated associations was assessed by a $95 \%$ confidence interval.

All analyses were conducted separately for boys and girls, and all results were adjusted for age. In additional analyses we also adjusted for school bullying (never, sometimes/very often, and unknown) and for pubertal development (early, on-time, late, and unknown). Moreover, in models examining the effect of physical activity we also adjusted for BMI (normal weight, underweight, overweight, and unknown), whereas models examining the effect of body composition were adjusted for days of physical activity per week (4-7 days, 2-3 days, 1 day and less than 1 day of physical activity per week).

When relevant, trend tests across categories of physical activity and BMI were calculated by treating the categories as an ordinal variable in the regression model. All statistical tests were two-sided, and all statistical analyses were completed using SPSS for Windows, version 15.0 (SPSS Inc. Headquarters, 233 S. Wacker Drive, 11th floor, Chicago, Illinois 60606, USA).

\section{Ethics}

All participants gave their written consent to take part in the study. For students younger than 16 years, parents also gave their written consent. The study was approved by the Regional Committee for Ethics in Medical Research and the Norwegian Data Inspectorate. The Nord-Trøndelag Health study (HUNT) Research Center gave permission to analyze the data from Young-HUNT 1 and Young-HUNT 2. 
Table 1. Characteristics of the study population.

\begin{tabular}{|c|c|c|c|c|}
\hline \multirow[b]{2}{*}{ Variables } & \multicolumn{2}{|r|}{ Girls } & \multicolumn{2}{|r|}{ Boys } \\
\hline & $\begin{array}{c}\text { No. of } \\
\text { participants }\end{array}$ & $\begin{array}{c}\text { No. (\%) with } \\
\text { depression/anxiety }\end{array}$ & $\begin{array}{c}\text { No. of } \\
\text { participants }\end{array}$ & $\begin{array}{c}\text { No. }(\%) \text { with } \\
\text { depression/anxiety }\end{array}$ \\
\hline \multicolumn{5}{|l|}{ Age groups } \\
\hline$<14$ & 365 & $91(24.9)$ & 367 & $43(11.7)$ \\
\hline 14 & 372 & $92(24.7)$ & 342 & $37(10.8)$ \\
\hline$\geq 15$ & 272 & $46(16.9)$ & 272 & $25(9.19)$ \\
\hline \multicolumn{5}{|l|}{ Body mass index ${ }^{a}$} \\
\hline Underweight & 62 & $13(20.6)$ & 44 & $7(15.9)$ \\
\hline Normal weight & 777 & $162(20.8)$ & 739 & $83(11.2)$ \\
\hline Overweight & 129 & $35(27.1)$ & 76 & $8(10.5)$ \\
\hline Obese & 20 & $6(30.0)$ & 66 & $6(9.1)$ \\
\hline \multicolumn{5}{|l|}{ Divorced parents } \\
\hline No & 813 & $161(19.8)$ & 767 & $79(10.3)$ \\
\hline Yes & 178 & $64(36.0)$ & 149 & $22(14.8)$ \\
\hline \multicolumn{5}{|l|}{ School bullying } \\
\hline No & 916 & $202(22.1)$ & 773 & $75(9.7)$ \\
\hline Yes & 81 & $21(25.9)$ & 163 & $28(17.2)$ \\
\hline \multicolumn{5}{|c|}{ Pubertal development score } \\
\hline Low & 162 & $30(18.5)$ & 131 & $8(6.1)$ \\
\hline Medium & 478 & $106(22.2)$ & 382 & $47(12.3)$ \\
\hline High & 308 & $74(24.0)$ & 245 & $27(10.6)$ \\
\hline
\end{tabular}

${ }^{a}$ Cut-offs defined by International Obesity Task Force classification described by Cole et al. (2000)

\section{RESULTS}

Descriptive characteristics of the study population are presented in Table 1. Since all adolescents did not respond to all questions, the total number of respondents for each variable may vary. Based on information of SCL-5 scores for 1009 girls and 950 boys, we found that 229 girls $(22.7 \%)$ and 105 boys $(11.1 \%)$ could be classified as having symptoms of anxiety/depression. Moreover, information on general well-being classified $131(12.7 \%)$ girls and $68(7.0 \%)$ boys as dissatisfied with life, and $120(11.6 \%)$ girls and $103(10.6 \%)$ boys as downhearted.

\section{Physical activity and anxiety/depression risk}

As shown in Table 2, there was little effect of exercise (days per week) on the risk for symptoms of anxiety/ depression among girls (P-trend, 0.34), whereas among boys, days of physical activity per week showed an inverse association with the risk for symptoms of anxiety/depression (P-trend, 0.02). Boys who reported to be physically active less than one day a week had twice the risk for symptoms of anxiety/depression compared to those who reported to be physically active four days or more per week (RR, 2.1; 95\% CI, 1.2-3.7).

There was no evidence of a linear association for hours of weekly physical activity and risk for symptoms of anxiety/depression, neither for girls (P-trend, 0.16 ) nor for boys (P-trend, 0.24. However, girls who reported that they used to be active had a RR of 1.3 (95\% CI, 1.0-1.7) compared to active girls, whereas a similar comparison among boys showed no association (RR, 1.0; 95\% CI, 0.8-2.4).

The results also show that adolescents who participated in different kind of sports overall had lower risks (most RRs <1.0) compared with the reference group of no activity, but small numbers of adolescents in the different sport categories make the estimated risks unstable and unprecise.

\section{Body composition and anxiety/depression risk}

Overall, there was no statistically significant association between various measures of body composition and risk for symptoms of anxiety/depression (Table 3). However, boys who were classified as underweight had a RR of 1.6 (95\% CI, 0.8-3.2). Moreover, girls who considered themselves "very fat/chubby" or "thin/very thin" had a higher risk than those who considered themselves as "about the same as others" (the RRs were $1.4 ; 95 \% \mathrm{CI}, 1.0-1.7$ and $1.7 ; 95 \% \mathrm{CI}, 0.8-1.4$, respectively). In boys, the risk was highest for those who considered themselves as "thin/very thin" (RR, $1.7 ; 95 \%$ CI, 1.1-2.7).

\section{Downheartedness and dissatisfaction with life}

Table 4 shows that the risk of being downhearted were higher for both underweight and overweight girls, compared to normal weighted girls (RRs were 2.1; 95\% CI, 1.2-3.5 and 1.5; 95\% CI, 1.0-1.3, respectively), whereas among boys there were no clear associations. Analysis of body image showed that boys and girls who considered themselves as "very fat/chubby" 
Table 2. Relative risks for symptoms of Anxiety/Depression (SCL-5 $\geq 2$ ) associated with physical activity among 2000 Norwegian adolescents.

\begin{tabular}{|c|c|c|c|c|c|c|c|c|c|c|}
\hline \multirow[b]{2}{*}{ Physical activity } & \multicolumn{5}{|c|}{ Girls } & \multicolumn{5}{|c|}{ Boys } \\
\hline & $\begin{array}{l}\text { No. of } \\
\text { persons }\end{array}$ & $\begin{array}{c}\text { No. of } \\
\text { cases }\end{array}$ & $\mathrm{RR}^{\mathrm{a}}$ & $\mathrm{RR}^{\mathrm{b}}(95 \% \mathrm{CI})$ & P-trend ${ }^{\mathrm{c}}$ & $\begin{array}{l}\text { No. of } \\
\text { persons }\end{array}$ & $\begin{array}{l}\text { No. of } \\
\text { cases }\end{array}$ & $\mathrm{RR}^{\mathrm{a}}$ & $\mathrm{RR}^{\mathrm{b}}(95 \% \mathrm{CI})$ & P-trend ${ }^{c}$ \\
\hline \multicolumn{11}{|l|}{ Days per week } \\
\hline$\geq 4$ days & 247 & 57 & 1.0 & 1.0 (Reference) & & 346 & 30 & 1.0 & 1.0 (Reference) & \\
\hline 2-3 days & 489 & 106 & 0.9 & $1.0(0.8-1.3)$ & & 409 & 49 & 1.4 & $1.4(0.9-2.1)$ & \\
\hline 1 day & 132 & 31 & 1.0 & $1.1(0.7-1.6)$ & & 108 & 12 & 1.3 & $1.3(0.7-2.5)$ & \\
\hline$<1$ day & 137 & 34 & 1.1 & $1.2(0.8-1.7)$ & 0.34 & 81 & 14 & 2.0 & $2.1(1.2-3.7)$ & 0.02 \\
\hline \multicolumn{11}{|l|}{ Hours per week } \\
\hline$\geq 7$ hours & 73 & 14 & 1.0 & 1.0 (Reference) & & 162 & 15 & 1.0 & 1.0 (Reference) & \\
\hline 4-6 hours & 292 & 65 & 1.1 & $1.2(0.8-2.3)$ & & 293 & 29 & 1.1 & $1.1(0.6-1.9)$ & \\
\hline 2-3 hours & 357 & 78 & 1.1 & $1.1(0.7-1.8)$ & & 269 & 32 & 1.3 & $1.3(0.7-2.3)$ & \\
\hline$\leq 1$ hour & 279 & 70 & 1.3 & $1.4(0.8-2.2)$ & 0.16 & 219 & 28 & 1.4 & $1.3(0.7-2.4)$ & 0.24 \\
\hline \multicolumn{11}{|l|}{ Active in sports } \\
\hline Yes & 668 & 142 & 1.0 & 1.0 (Reference) & & 653 & 69 & 1.0 & 1.0 (Reference) & \\
\hline Previously & 230 & 59 & 1.3 & $1.3(1.0-1.7)$ & & 201 & 22 & 1.1 & $1.0(0.6-1.6)$ & \\
\hline No & 109 & 27 & 1.2 & $1.2(0.9-1.8)$ & - & 94 & 14 & 1.4 & $1.4(0.8-2.4)$ & - \\
\hline \multicolumn{11}{|l|}{ Type of activity } \\
\hline No activity & 101 & 25 & 1.0 & 1.0 (Reference) & & 91 & 14 & 1.0 & 1.0 (Reference) & \\
\hline Endurance & 159 & 36 & 0.9 & $0.9(0.6-1.4)$ & & 226 & 23 & 0.6 & $0.6(0.4-1.2)$ & \\
\hline Strength & 10 & 5 & 2.0 & $2.0(1.0-4.0)$ & & 49 & 4 & 0.5 & $0.6(0.2-1.6)$ & \\
\hline Ball & 423 & 88 & 0.8 & $0.8(0.5-1.2)$ & & 425 & 45 & 0.7 & $0.7(0.4-1.2)$ & \\
\hline Esthetics & 253 & 61 & 1.0 & $1.0(0.6-1.4)$ & & 64 & 5 & 0.5 & $0.5(0.2-1.4)$ & \\
\hline Others & 40 & 8 & 0.8 & $0.8(0.4-1.7)$ & - & 45 & 4 & 0.6 & $0.6(0.2-1.9)$ & - \\
\hline
\end{tabular}

Abbreviations: $\mathrm{RR}=$ relative risk, $\mathrm{CI}=$ confidence interval

${ }^{\text {a }}$ Adjusted for age

${ }^{\mathrm{b}}$ Adjusted for age, school bullying, pubertal development, and body mass index

${ }^{\mathrm{c}} \mathrm{P}$-value from trend test when categories were entered as an ordinal variable in the regression model

Table 3. Relative risks for symptoms of Anxiety/Depression (SCL-5 $\geq 2$ ) associated with body composition and body image among 2000 Norwegian adolescents.

\begin{tabular}{|c|c|c|c|c|c|c|c|c|c|c|}
\hline \multirow[b]{2}{*}{ Variable } & \multicolumn{5}{|c|}{ Girls } & \multicolumn{5}{|c|}{ Boys } \\
\hline & $\begin{array}{c}\text { No. of } \\
\text { persons }\end{array}$ & $\begin{array}{c}\text { No. of } \\
\text { cases }\end{array}$ & $\mathrm{RR}^{\mathrm{a}}$ & $\mathrm{RR}^{\mathrm{b}}(95 \% \mathrm{CI})$ & P-trend ${ }^{\mathrm{c}}$ & $\begin{array}{l}\text { No. of } \\
\text { persons }\end{array}$ & $\begin{array}{l}\text { No. of } \\
\text { cases }\end{array}$ & $\mathrm{RR}^{\mathrm{a}}$ & $\mathrm{RR}^{\mathrm{b}}(95 \% \mathrm{CI})$ & P-trend ${ }^{\mathrm{C}}$ \\
\hline \multicolumn{11}{|l|}{ Body mass index ${ }^{\mathrm{d}}$} \\
\hline Underweight & 162 & 13 & 1.0 & $1.0(0.6-1.8)$ & & 44 & 7 & 1.4 & $1.6(0.8-3.2)$ & \\
\hline Normal weight & 777 & 162 & 1.0 & 1.0 (Reference) & & 739 & 83 & 1.0 & 1.0 (Reference) & \\
\hline Overweight/obese & 615 & 31 & 1.0 & $1.2(0.9-1.6)$ & 0.31 & 142 & 14 & 0.9 & $0.8(0.4-1.3)$ & 0.10 \\
\hline \multicolumn{11}{|l|}{ Waist circumference ${ }^{\mathrm{e}}$} \\
\hline Low & 168 & 34 & 1.0 & $1.0(0.7-1.4)$ & & 161 & 23 & 1.3 & $1.5(0.9-2.3)$ & \\
\hline Medium & 604 & 129 & 1.0 & 1.0 (Reference) & & 563 & 60 & 1.0 & 1.0 (Reference) & \\
\hline High & 206 & 49 & 1.1 & $1.1(0.8-1.4)$ & 0.68 & 197 & 21 & 1.0 & $0.9(0.5-1.4)$ & 0.07 \\
\hline \multicolumn{11}{|l|}{ Waist/hip ratio ${ }^{\mathrm{e}}$} \\
\hline Low & 193 & 39 & 1.0 & $0.9(0.7-1.3)$ & & 115 & 16 & 1.2 & $1.2(0.7-1.9)$ & \\
\hline Medium & 588 & 126 & 1.0 & 1.0 (Reference) & & 437 & 53 & 1.0 & 1.0 (Reference) & \\
\hline High & 197 & 47 & 1.1 & $1.1(0.8-1.4)$ & 0.56 & 365 & 33 & 0.8 & $0.7(0.5-1.1)$ & 0.06 \\
\hline \multicolumn{11}{|l|}{ Self-perception } \\
\hline Very fat/chubby & 282 & 78 & 1.3 & $1.4(1.0-1.7)$ & & 168 & 20 & 1.3 & $1.1(0.7-1.7)$ & \\
\hline Same as others & 590 & 119 & 1.0 & 1.0 (Reference) & & 604 & 57 & 1.0 & 1.0 (Reference) & \\
\hline Thin/very thin & 122 & 27 & 1.2 & $1.7(0.8-2.4)$ & - & 158 & 24 & 1.6 & $1.7(1.1-2.7)$ & - \\
\hline
\end{tabular}

Abbreviations: $\mathrm{RR}=$ relative risk, $\mathrm{CI}=$ confidence interval

${ }^{\text {a }}$ Adjusted for age

${ }^{\mathrm{b}}$ Adjusted for age, school bullying, pubertal development, and days of physical activity

${ }^{\mathrm{c}} \mathrm{P}$-value from trend test when categories were entered as an ordinal variable in the regression model

${ }^{\mathrm{d}}$ Cut-offs defined by International Obesity Task Force classification described by Cole et al. (2000)

${ }^{\mathrm{e}}$ Waist circumference and waist-hip ratio classified according to age and gender specific cut-offs (quintiles; and collapsing the three middle fifths in the analysis) 
Table 4. Relative risks for feeling downhearted or dissatisfied with life associated with physical activity, body composition, and body image among 2000 Norwegian adolescents.

\begin{tabular}{|c|c|c|c|c|}
\hline & \multicolumn{2}{|c|}{ Downhearted } & \multicolumn{2}{|c|}{ Dissatisfied with life } \\
\hline & Girls & Boys & Girls & Boys \\
\hline & $\mathrm{RR}^{\mathrm{a}}(95 \% \mathrm{CI})$ & $\mathrm{RR}^{\mathrm{a}}(95 \% \mathrm{CI})$ & $\mathrm{RR}^{\mathrm{a}}(95 \% \mathrm{CI})$ & $\mathrm{RR}^{\mathrm{a}}(95 \% \mathrm{CI})$ \\
\hline \multicolumn{5}{|c|}{ Physical activity per week } \\
\hline$\geq 4$ days & 1.0 (Reference) & 1.0 (Reference) & 1.0 (Reference) & 1.0 (Reference) \\
\hline 2-3 days & $1.9(1.1-3.2)$ & $1.6(1.0-2.6)$ & $1.3(0.9-2.1)$ & $1.7(0.9-3.3)$ \\
\hline 1 day & $2.1(1.1-3.9)$ & $1.3(0.7-2.6)$ & $1.5(0.9-2.6)$ & $2.0(0.9-4.3)$ \\
\hline$<1$ day & $2.3(1.2-4.2)$ & $1.9(1.0-3.5)$ & $1.7(1.0-2.9)$ & $2.7(1.3-5.7)$ \\
\hline \multicolumn{5}{|l|}{ Body mass index ${ }^{b}$} \\
\hline Underweight & $2.1(1.2-3.5)$ & $0.7(0.3-1.9)$ & $1.7(1.0-2.9)$ & $0.4(0.1-2.6)$ \\
\hline Normal weight & 1.0 (Reference) & 1.0 (Reference) & 1.0 (Reference) & 1.0 (Reference) \\
\hline Overweight/obese & $1.5(1.0-2.3)$ & $0.9(0.6-1.5)$ & $2.0(1.4-2.8)$ & $1.7(1.0-2.7)$ \\
\hline \multicolumn{5}{|l|}{ Self-perception } \\
\hline Very fat/chubby & $1.9(1.3-2.7)$ & $1.7(1.1-2.5)$ & $2.5(1.8-3.5)$ & $1.6(0.9-2.7)$ \\
\hline Same as others & 1.0 (Reference) & 1.0 (Reference) & 1.0 (Reference) & 1.0 (Reference) \\
\hline Thin/very thin & $1.3(0.8-2.3)$ & $1.0(0.6-1.8)$ & $1.6(0.9-2.7)$ & $1.2(0.6-2.3)$ \\
\hline
\end{tabular}

Abbreviations: $\mathrm{RR}=$ relative risk, $\mathrm{CI}=$ confidence interval

${ }^{a}$ Adjusted for age, school bullying, and pubertal development (analyses of body mass index and body image were also adjusted for physical activity, whereas analysis of physical activity were adjusted for body mass index)

${ }^{\mathrm{b}}$ Cut-offs defined by International Obesity Task Force classification described by Cole et al. (2000)

had a substantial higher risk of feeling downhearted than the reference group (the RR was $1.9 ; 95 \% \mathrm{CI}$, 1.3-2.7 among girls and 1.7; 95\% CI, 1.1-2.5 among boys). There was an inverse association between days of physical activity and risk of reporting low mood both among girls and boys. Girls who reported being physical active less than one day per week had a RR of 2.3 (95\% CI, 1.2-4.2) whereas the corresponding association among boys was 1.9 (95\% CI, 1.0-3.5).

Relative risks associated with reporting dissatisfaction with life (Table 4) followed a largely similar pattern as those associated with feeling downhearted. The relative risk was higher among underweight and overweight girls (the RRs were 1.7; 95\% CI, 1.0-2.9 and $2.0 ; 95 \%$ CI, 1.4-2.8, respectively), compared to those with normal weight. Furthermore, boys who were classified as overweight had a higher risk than normal weight boys (RR, 1.7; 95\% CI, 1.0-2.7). Girls and boys who considered themselves "very fat/chubby" had a RR of 2.5 (95\% CI, 1.8-3.5) and 1.6 (95\% CI, $0.9-2.7)$, respectively, whereas girls who considered themselves "thin/very thin" had a RR of $1.6(95 \% \mathrm{CI}$, $0.9-2.7)$. Table 4 also shows that the risk of reporting dissatisfactions with life was inversely associated with days of physical activity per week, both among girls and boys.

\section{Discussion}

The symptoms of anxiety/depression were twice as high among girls (22.7\%) as among boys (11.1\%). Days of physical activity per week showed an inverse association with the risk for symptoms of anxiety/ depression in boys, and with the risk of feeling down- hearted and dissatisfied with life in both genders. Girls who considered themselves as "very fat/chubby" and boys who considered themselves "thin/very thin" had a significantly higher risk for symptoms of anxiety/ depression compared to the reference group who considered themselves as "about the same as others", and body image also influenced the risk for reporting downheartedness and dissatisfaction with life. In addition, the risks of feeling downhearted and dissatisfied with life were higher for both underweight and overweight girls, compared to girls with normal weight.

The higher occurrence of symptoms of anxiety/depression among girls compared to boys in this study is consistent with findings from other studies (Grøtvedt \& Gimmestad, 2002; Substance Abuse and Mental Health Services Administration, 2008; Wichstrøm, 1999). Social relationship may be more important for girls, and they may be more vulnerable to loss of social relationship than boys (Allgood-Merten et al., 1990). Girls may experience and cope with stress different than boys (Nolen-Hoeksema \& Girgus, 1994). Our results showed that among adolescents with divorced parents, $36 \%$ of girls, and $15 \%$ of boys were categorized as having symptoms of anxiety/depression. Girls may need a higher degree of support, approval, and success to feel confident than boys (Calvete and Cardenso, 2005). The biological and hormonal changes during puberty may also be important for the higher scores of symptoms of depression among adolescent girls than among boys (Hankin \& Abramson, 2001).

Other studies have also found a relation between mental health and physical activity (Sallis et al., 2000; Sagatun et al., 2007; Brosnahan et al., 2004), and several mechanisms may explain why physical activity 
and exercise may influence mental health and mood positively. Participating in exercise may lead to friendship, social contact, less negative thoughts, and a positive self-concept (Lepore, 1997). Building healthy selfesteem through social involvement and friendship may be an important aspect of activity in addition to the physiological gains of been active during the youth years.

Changes in endorphin and monoamine levels or reduction in the levels of the stress hormone cortisol are all physiological effects resulting from exercise, and may improve mood (Duclos et al., 2003). Girls experiencing early menarche and early pubertal development have an increased risk for symptoms of depression in adolescence (Kaltiala-Heino et al., 2003). However, girls participating in sport during adolescents often have a delayed age of menarche.

Adolescence is a vulnerable developmental period that may introduce concerns over a changing body coposition and body size (Erermis et al., 2004; Wardle et al., 2006). Obese adolescents may experience social rejection, discrimination, and negative stereotyping that leads to negative perception of body image and reduced self-esteem and mood (Wardle \& Cooke, 2005; Cortese et al., 2009; Erermis et al., 2004; Vila et al., 2004). However, Wardle and Cooke (2005) concluded from their review that even if levels of body dissatisfaction were higher in community samples of overweight and obese adolescents than in their normal counterparts, few were significantly depressed or had low self-esteem.

Our results showed that girls classified as overweight and boys classified as underweight more frequently reported symptoms of anxiety/depression compared to normal weight adolescents. Participation in certain sports may lead to more muscle mass and bigger bodies. Thinness may often be perceived as preferable for young women, whereas for men the ideal may be more a muscular body. Our results support these social preferences.

The association between body image and risk of symptoms of anxiety/depression is noteworthy. The girls who considered themselves very fat/chubby and thin/very thin had significantly higher risk than did girls who considered themselves about the same as others. Among boys, those who considered themselves as underweight had the highest risk for symptoms of anxiety/depression. This is in accordance to the literature related to eating disorders. The perception of the body image is important, not only the actually body weight (Daniels, 2005).

The strength of this study includes the large number of adolescents and the population-based longitudinal study design. We could exclude those with serious health problems at baseline, and control for possible confounders. However, biased estimates due to confounding by unmeasured and unknown factors cannot be excluded in this type of study. In spite of the rather high participation rate, about $20 \%$ did not take part in Young-HUNT 2. This health study was organized through the local school system. If it had been possible to include those who dropped out of school or moved, it may have influenced the results. However, the direction and the magnitude of such an effect are difficult to predict.

\section{Conclusions}

The findings indicated that physical activity may reduce the risk of anxiety/depression in boys, but not in girls. In both genders, however, physical activity was inversely related to the risk of feeling downhearted and dissatisfied with life. The results showed an association between body image and risk for symptoms of anxiety/depression, but different direction for boys compared to girls, whereas body size and body composition showed no clear association with measures of mental health in either gender. Overall, the results suggest that self-perception of appearance are more important for mental health in adolescents than the actual body composition, and that being physically active is beneficial, especially among boys.

\section{ACKNOWLEDGEMENT}

Nord-Trøndelag Health Study (The HUNT Study) is a collaboration between HUNT Research Centre (Faculty of Medicine, Norwegian University of Science and Technology NTNU), Nord-Trøndelag County Council and The Norwegian Institute of Public Health.

\section{REFERENCES}

Ainsworth BE, Richardson, MT, Jacobs DR, Leon AS, Sternfeld B (1999). Accuracy of recall of occupational physical activity by questionnaire. J Clin Epidemiol, 52 (3), 219-227.

Allgood-Merten BB, Lewinsohn PPM, Hops HH (1990). Sex differences and adolescent depression. J Abnorm Psychol, 99 (1), 55-63.

Booth M, Okely A, Chey T, Bauman A (2001). The reliability and validity of the physical activity questions in the WHO health behaviour survey: a population study. Br J Sports Med, 35, 263-267.

Bratberg G, Nilsen T, Holmen T, Vatten L (2007). Early sexual maturation, central adiposity and subsequent overweight in late adolescence. A four-year follow-up of 1605 adolescent Norwegian boys and girls: the Young HUNT study. BMC Public Health, 7 (1), 54.

Brosnahan J, Steffen LM, Lytle L, Patterson J, Boostrom A (2004). The relation between physical activity and mental health among hispanic and non-hispanic white adolescents. Arch Pediatr Adolesc Med, 158, 818-823. 
Calfas KJ, Taylor WC (1994). Effects of physical activity on psychological variables in adolescents. Pediatr Exerc Sci, 6, 406-423.

Calvete E, Cardenso O (2005). Gender differences in cognitive vulnerability to depression and behavior problems in adolescents. J Abnorm Child Psychol, 33 (2), 179-192.

Cole TJ, Bellizzi MC, Flegal KM, Dietz WH (2000). Establishing a standard definition for child overweight and obesity worldwide: international survey. $\operatorname{Br}$ Med $J, 320$ (7244), 1240.

Cortese S, Falissard B, Angriman M, Pigaiani Y, Banzato C, Bogoni G, et al. (2009). The relationship between body size and depression symptoms in adolescents. J Pediatrics, 154 (1), 86-90.

Daniels J (2005). Weight and weight concerns: are they associated with reported depressive symptoms in adolescents? J Pediatric Health Care, 19 (1), 33-41.

Daniels SR, Khoury PR, Morrison JA (2000). Utility of different measures of body fat distribution in children and adolescents. Am J Epidemiol, 152 (12), 1179-1184.

Duclos M, Gouarne C, Bonnemaison D. (2003). Acute and chronic effects of exercise on tissue sensitivity to glucocorticoids. J Appl Physiol, 94 (3), 869-875.

Erermis S, Cetin N, Tamar M, Bukusoglu N, Akdeniz F, Goksen D (2004). Is obesity a risk factor for psychopathology among adolescents? Pediatr Int, 46 (3), 296-301.

Goran M, Gower B, Treuth M, Nagy T (1998). Prediction of intra-abdominal and subcutaneous abdominal adipose tissue in healthy pre-pubertal children. Int J Obes Rel Metabol Disord, 22, 549-558.

Grøtvedt L, Gimmestad A (2002). Helseprofil for Oslo, barn og unge. Oslo: Nasjonalt Folkehelseinstitutt.

Hankin BL, Abramson LY (2001). Development of gender differences in depression: an elaborated cognitive vulnerability-transactional stress theory. Psychol Bull, 127 (6), 773-796.

Holmen TL, Barrett-Connor E, Clausen J, Holmen J, Bjermer L (2002). Physical exercise, sports, and lung function in smoking versus nonsmoking adolescents. Eur Resp J, 19 (1), 8-15.

Kaltiala-Heino R, Marttunen M, Rantanen P, Rimpelä M (2003). Early puberty is associated with mental health problems in middle adolescence. Soc Sci Med, 57 (6), 1055-1064.

Kohl HW, Fulton JE, Caspersen CJ (2000). Assessment of physical activity among children and adolescents: A systematic review. Prevent Med, 31, 54-76.

Larun L, Nordheim L, Ekeland E, Hagen K, Heian F (2003). Exercise in prevention and treatment of anxiety and depression among children and young people. Cochrane Database of Systematic Reviews (4).

Lepore SJ (1997). Expressive writing moderates the relation between intrusive thoughts and depressive symptoms. J Pers Soc Psychol, 73 (5), 1030-1037.

Motl RW, Birnbaum AS, Kubik MY, Dishman RK (2004). Naturally occurring changes in physical activity are inversely related to depressive symptoms during early adolescence. Psychosom Med, 66 (3), 336-342.

Mutrie N, Parfitt G (1998). Physical activity and its link with mental, social and moral health in young people. In: Biddle S, Sallis J (Eds.), Young and active (pp. 46-68). London: Health Education Authority.

Nolen-Hoeksema SS, Girgus JS (1994). The emergence of gender differences in depression during adolescence. Psychol Bull, 115 (3), 424-443.

Ozmen D, Ozmen E, Ergin D, Cetinkaya A, Sen N, Dundar P, et al. (2007). The association of self-esteem, depression and body satisfaction with obesity among Turkish adolescents. BMC Public Health, 7 (1), 80.

Paus T, Keshavan M, Giedd JN (2008). Why do many psychiatric disorders emerge during adolescence? Nature Rev Neurosci, 9 (12), 947-957.

Rangul V, Holmen TL, Kurtze N, Cuypers K, Midthjell K (2008). Reliability and validity of two frequently used self-administered physical activity questionnaires in adolescents. BMC Med Res Methol, 8, 47.

Sagatun A, Søgaard AJ, Bjertness E, Selmer R, Heyerdahl S (2007). The association between weekly hours of physical activity and mental health: A three-year-follow-up study of 15-16-year-old students in the city of Oslo, Norway. BMC Public Health, 7, 155.

Sallis JF, Prochaska JJ, Taylor WC (2000). A review of correlates of physical activity of children and adolescents. Med Sci Sports Exerc, 32 (5), 963-975.

Schonert-Reichl KA, Muller JR (1996). Correlates of help-seeking in adolescence. J Youth Adolesc, 25 (6), 705 731.

Shephard RJ (2003). Limits to the measurement of habitual physical activity by questionnaires. Br J Sports Med, 37 (3), 197-206.

Steptoe A, Butler N (1996). Sports participation and emotional wellbeing in adolescents. Lancet, 347 (9018), 1789-1792.

Strand B, Dalgard O, Tambs K, Rognerud M (2003). Measuring the mental health status of the Norwegian population: a comparison of the instruments SCL-25, SCL-10, SCL-5 and MHI-5 (SF-36). Nord J Psychiatry, 57 (2), 113-118.

Substance Abuse and Mental Health Services Administration (2008). Results from the 2007 National Survey on Drug Use and Health: National Findings. Rockville: Office of Applied Studies. 
Tambs K, Moum T (1993). How well can a few questionnaire items indicate anxiety and depression? Acta Psychiatr Scand, 87, 364-367.

The Institute of Public Health (2009). Psykiske lidelser $i$ Norge: Et folkehelseperspektiv. Oslo: The Institute of Public Health.

Tollefsen E, Bjermer L, Langhammer A, Johnsen R, Holmen TL (2006). Adolescent respiratory symptoms - girls are at risk: The Young-HUNT study, Norway. Respir Med, 100 (3), 471-476.

Vila G, Zipper E, Dabbas M, Bertrand C, Robert JJ, Ricour C, et al. (2004). Mental disorders in obese children and adolescents. Psychosom Med, 66 (3), 387-394.

Wardle J, Brodersen N, Cole T, Jarvis M, Boniface D (2006). Development of adiposity in adolescence: five year longitudinal study of an ethnically and socioeconomically diverse sample of young people in Britain. $\mathrm{Br} \mathrm{Med}$ $J$, 332, 1130-1135.

Wardle J, Cooke L (2005). The impact of obesity on psychological well-being. Best Pract Res Clin Endocrinol Metab, 19 (3), 421-440.

Wichstrøm L (1999). The emergence of gender difference in depressed mood during adolescence: the role of intensified gender socialization. Dev Psychol, 35 (1), 232-245.

Wight RG, Sepulveda JE, Aneshensel CS (2004). Depressive symptoms: how do adolescents compare with adults? J Adolesc Health, 34 (4), 314-323. 